\title{
CIRCUIT DESIGN FOR MEASUREMENT OF FORCE IN BIAXIAL AREA
}

\author{
SKOCIK, P[etr] \& NEUMANN, P[etr]
}

\begin{abstract}
This contribution is focused on circuit design for measurement of speed and direction of wind. The measurement method is based on balance of strain gauge sensors on the deformation unit which are connected to the bridge. The sensor reacts to the mechanical force in biaxial area. The semiconductor strain gauges are used in this work. They have a very considerable and accurate change of the electrical resistance with applied mechanical strain. Evaluation is realized as a voltage difference. This measurement is a part of the model of Photovoltaic unit.
\end{abstract}

Key words: strain gauges, operational amplifiers, mechanical force, DataLab

\section{INTRODUCTION}

This paper presents a circuit design for measurement of forces in biaxial area which is used for evaluation of speed and direction of wind. This evaluation is a part of the Photovoltaic unit. This model (DE10) is an experimental laboratory exercise in the project of online available real models. This modern laboratory contains series of real-time models which can be accessed from campus LAN or remotely from the Internet. All models are used for education in the study programs related to the industrial automation and to the applied informatics. The main goal for the future is to become a part of the global laboratories on the Internet (Hruška 2005). 2009):

The DE10 model has the following functions (Hruška,

- Biaxial positioning of the panel via the step motors (azimuth and elevation)

Measurement of:

- $\quad$ wind speed and direction

- temperature, humidity and barometer pressure

- illumination

- electric parameters of the panel and battery

- voltage of module and battery

- azimuth and elevation

As was already mentioned before, this work is focused on one part from the list which is the measurement of the wind speed and direction.

\section{MEASUREMENT PRINCIPLE}

The non rotating principle was used for the evaluation of acting force. Therefore, a sensor with strain gauges was designed for the purpose of biaxial force measurement.

The deformation unit must hold the force in $x$ axis $\left(F_{X}\right)$ constant when the force in $y$ axis $\left(\mathrm{F}_{\mathrm{Y}}\right)$ changes and conversely. This demand is fulfilled by the hollow deformation unit as can be seen in Fig. 1.

The deformation unit is exposed to the wind flow. The bridge connection of the strain gauges provides two output voltages $U_{X}$ and $U_{Y}$ which are adjusted and analyzed.

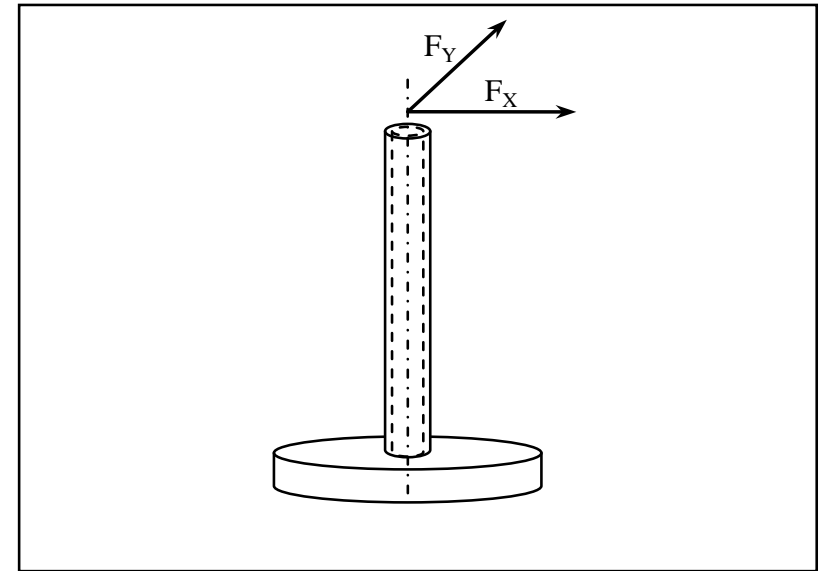

Fig. 1. Deformation unit

The Newton law applies (Černý et al., 2007):

$$
\frac{1}{2} k S \rho v^{2}=F
$$

$$
\begin{aligned}
& \text { where } \quad \mathrm{F} \text { - force }(\mathrm{N}) \\
& k \text { - coefficient } \\
& \mathrm{S} \text { - panel surface }(\mathrm{m} 2) \\
& \rho \text { - fluid density }(\mathrm{kg} / \mathrm{m} 3) \\
& \mathrm{v} \text { - flow speed }(\mathrm{m} / \mathrm{s}) \text {. }
\end{aligned}
$$

Values of the coefficient $k$ are: for circular plate $k=1.11$, square plate $k=1.27$, cylinder $k=1.2$.

Further, following relations applies according to the Fig. 2:

$$
\begin{gathered}
F_{X}^{2}+F_{Y}^{2}=F^{2} \\
\frac{F_{Y}}{F_{X}}=\tan \varphi
\end{gathered}
$$

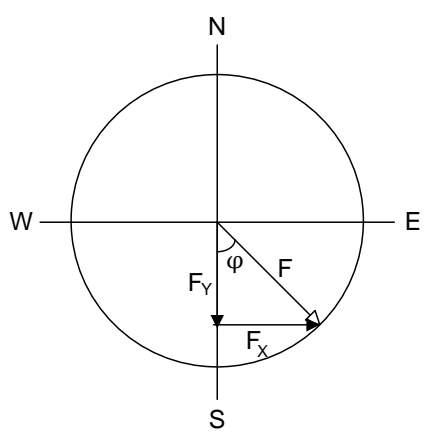

Fig. 2. Forces acting on the deformation unit 


\section{DESIGN OF THE CIRCUIT}

Block circuit diagram of the measuring system can be seen in Fig. 3 (Skočík et al., 2008). It consists from three main parts. One part is sensitive to the external impulses (sensors), second one serves for the adjusting of measured signals. The last part is used for the data evaluation and archiving (DataLab, PC).

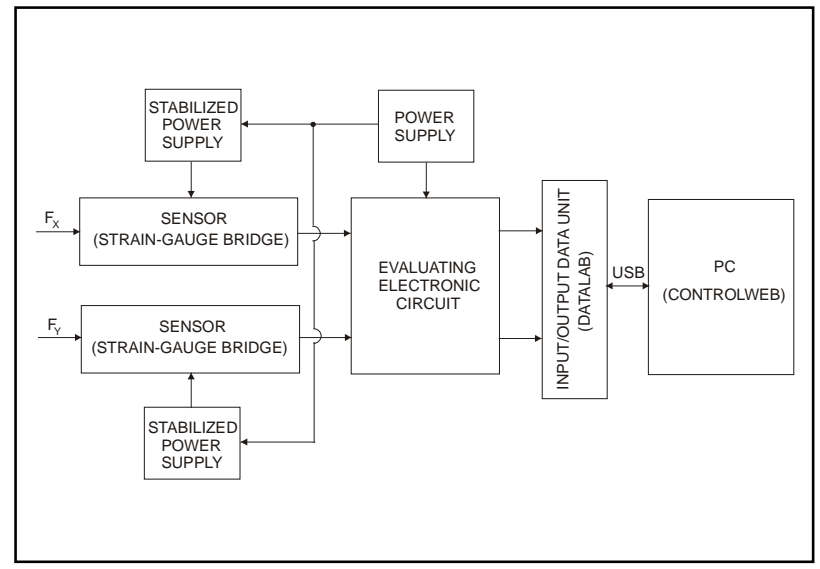

Fig. 3. Block circuit diagram of the measuring system

The deformation unit is stressed in two axes by forces $F_{X}$ and $F_{Y}$. The mechanical strain is measured for both directions by the semiconductor strain gauges in the bridge connection.

The semiconductor strain gauges were used in this work. They have a highest known efficiency in conversion of mechanical strain to the electrical resistance.

The advantages of the sensors with these strain gauges can be seen in $(* * *, 2010)$ :

- Quite high output signal in the range from tens to hundreds of $\mathrm{mV}$ DC

- Can be used in the environment with electromagnetic interference

- Minimal demand to the power supply capacity

- High lifetime

- Resistance to the overload up to $200 \%$ of nominal range

- High reliability

- Accuracy from $0.1 \%$

- Thermal drift of the zero value less than $0.02 \% /{ }^{\circ} \mathrm{C}$

- Thermal drift of the sensitivity less than $0.03 \% /{ }^{\circ} \mathrm{C}$

- Hysteresis in the nominal load is under $0.05 \%$

- Long-term stability in range from 0.015 to $0.05 \%$ per year

Both output voltages $\mathrm{U}_{\mathrm{X}}, \mathrm{U}_{\mathrm{Y}}$ are adjusted and amplified by the low noise operational amplifiers TL071C and TL082C (see Fig. 4). These output signals are gained through the input/output unit DataLab to the PC where they are evaluated and archived in the ControlWeb environment. Communication and data transfer between the PC and DataLab unit is performed through the Universal Serial Bus (USB).

The output signal depends on the applied mechanical strain but also on the power supply current. Therefore, it is necessary to have the stabilized power supply.

Evaluation electronic circuits are powered by the symmetrical power supply $+/-15 \mathrm{~V}$ DC. This power supply powers also the ADR421 integrated circuits (Fig. 4) which give the stabilized voltage $2.5 \mathrm{~V}$ DC for the strain gauges (***, 2011).

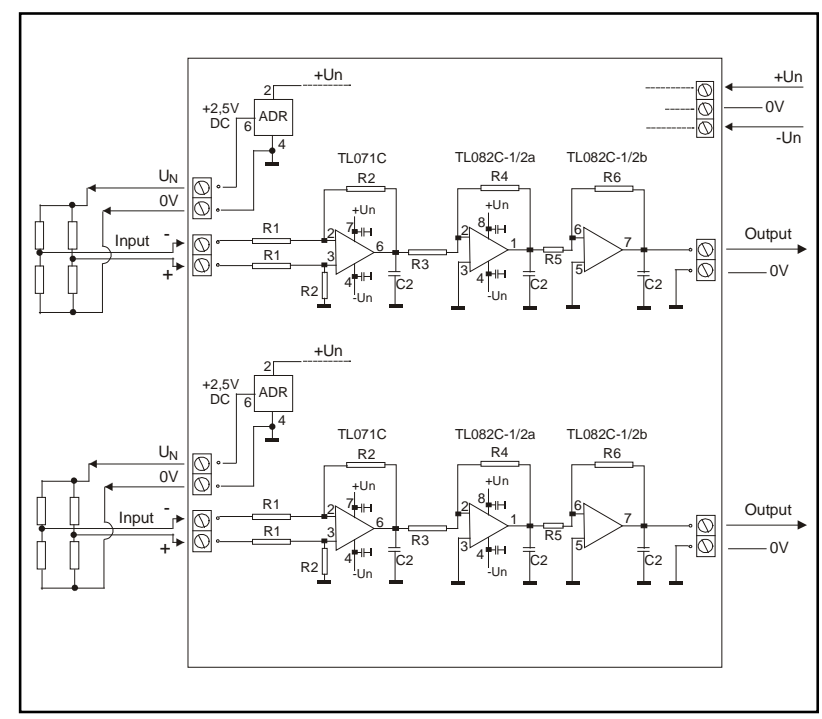

Fig. 4. Evaluation electronic circuit

\section{CONCLUSION}

The measurement was performed for the tested deformation unit. Tests are performed by connection of input-output data acquisition module and PC's program Control Web in the development version. Data are presented as relevance between mechanical force and output voltage from the measurement device. The results from the tests give positive signal for applying the sensor in measuring equipment for speed and direction of wind. Further, new operation amplifiers have to be used in the evaluation electronic circuit to achieve better parameters (accuracy, sensitivity, offset).

\section{ACKNOWLEDGEMENTS}

This work was accomplished with financial support by Research Projects of the Ministry of Youth, Education and Sports of the Czech Republic: MSM 7088352102 and by the European Regional Development Fund under the project CEBIA-Tech No. CZ.1.05/2.1.00/03.0089.

\section{REFERENCES}

Černý, F.; Samek, L. \& Sopko, B. (2007). Fyzika I. Vyd. 3. preprac. Praha : Vydavatelství ČVUT, 2007. 176 s. ISBN 978-80-01-03650-1.

Hruška, F. (2005). New laboratory of integrated automation. In.: Proceedings of the 16th International DAAAM Symposium, Opatia, Croatia, 19. - 22. October 2005, pp.165 - 166. ISBN 3-901509-46-1.

Hruška, F. (2009). Experimental photovoltaic system. In: Proceedings of the 20th International DAAAM Symposium. Vienna, Austria: 25. - 28. November 2009, pp. 923-924, ISBN 978-3-901509-70-4.

Skočík, P.; Hruška, F. \& Lkhagvatseren, T. (2008). Measurement of force in biaxial area. In: 8th International Scientific - Technical Conference PROCESS CONTROL. Kouty nad Desnou, Czech Republic: 9. - 12. June 2008, pp. 199, ISBN 978-80-7395-077-4.

*** (2010) http://www.vtsz.cz - VTS Zlin Associated Manufacturers, Semiconductor strain gauges in general and Basic range of our strain gauge, Accessed on: 2011-06-20

*** (2011) http://www.analog.com/static/imported-files /data_sheets/ADR420_421_423_425.pdf - Analog Devices, ADR421: Ultraprecision, Low Noise, 2.500 V XFET® ${ }^{\circledR}$ Accessed on: 2011-07-01 